Diaz Olvera L., Plat D., Pochet P. (2015), Assessment of mobility inequalities and income data collection. Methodological issues and a case study (Douala, Cameroon), Journal of Transport Geography, Vol. 46, pp. 180-188.

\title{
Assessment of mobility inequalities and income data collection. Methodological issues and a case study (Douala, Cameroon)
}

\author{
Lourdes DIAZ OLVERA, Didier PLAT and Pascal POCHET \\ Laboratoire d'Economie des Transports \\ ENTPE, CNRS, University of Lyon, France \\ lourdes.diaz-olvera@entpe.fr $\quad$ didier.plat@entpe.fr $\quad$ pascal.pochet@entpe.fr
}

\begin{abstract}
In order to understand the scale and nature of inequalities in intra-urban mobility we need reliable income data, but this is generally difficult to collect in household surveys. The methodological approaches that are employed to overcome difficulties in income data collection may affect the relative position of individuals and households within the income distribution and our estimates of mobility inequalities. In the context of a case study of Douala, this paper evaluates how the way income data is collected affects its accuracy and therefore the measurement of daily mobility inequalities. Simplified data collection tends to minimise the scale of inequalities as it misrepresents the income distribution. The error is greater in remote zones. Shortcomings in the statistical apparatus with regard to income data thus blur our perception of mobility inequalities and impede investigation of the links between daily travel, poverty and social exclusion.
\end{abstract}

\section{Key words}

Household travel survey, income data collection, daily mobility, transport expenditure, mobility inequality, sub-Saharan Africa

\section{Highlights}

- Income data collection impacts the measurement of daily mobility inequalities.

- Simplified income data collection misrepresents the income distribution.

- It leads to an underestimation of mobility inequalities.

- The level of underestimation depends on the mobility indicator.

- Errors are greater in the case of remote areas. 


\section{Assessment of mobility inequalities and income data collection. Methodological issues and a case study (Douala, Cameroon)}

\section{INTRODUCTION}

In metropolitan areas that are experiencing marked spatial growth, as is the case in sub-Saharan Africa, access to the activities and resources afforded by the city is far from universal. This is primarily because of socio-geographical disparities in the distribution of urban services and jobs (Myers, 2005; Rakodi, 2005). However, the situation is further worsened by major inequalities in the use of motorised transport modes, not only cars but also public transport which is too expensive for poor city-dwellers to use on a regular basis (Bryceson et al., 2003; Diaz Olvera et al., 2013; Lucas, 2011; Salon and Gulyani, 2010; Sietchiping et al., 2012). Differences between individuals' travel behaviours obviously exist, in the same way that there are differences between their state of health and access to healthcare and, in the case of the young, their possibility of going to school. When such differences between individuals result in disadvantages with regard to daily mobility, they are perceived as inequalities if they are due to situations that are partially or completely unchosen (income, gender, age, physical capacities, accessibility of residential location, etc.). In sub-Saharan Africa, transport policies take little account of the issues of social and geographical equity, i.e. the goal of fostering a more equal access to mobility, and, more broadly, to urban resources.

Investments in urban transport are usually focused on the construction and maintenance of roads and benefit primarily the minority of citizens with private cars (Vasconcellos, 2001). The Bus Rapid Transit systems which have recently been built, or which are currently planned, in many large African cities (Addis Abeba, Dakar, Dar es Salaam, Lagos, etc.) could indicate a change of policy direction, but it is still too early to assess if they will be affordable and located where they can serve low income populations. Both these conditions must be satisfied if the mobility of the poor is to improve. Teunissen et al. (2015) have shown, for example, in the case of Bogotá, that while the Transmilenio serves the zones with the greatest concentrations of poor people, its cost means they are unable to make much use of it. Such decisions on the part of the public authorities are explained by a variety of factors such as the role of international organisations and donors or the desire to have "modern" transport systems which use up-todate technology. But even if the public authorities wished to consider the impacts of transport policy with regard to equity, they would in most cases be unable to do so because of an absence of adequate statistical data. The knowledge of the scale and nature of intra-urban inequalities 
requires reliable statistics disaggregated by income group (Mitlin et al., 1996). Such income statistics must then be compared with travel behaviours. But as the investigation of travel issues is frequently concerned with engineering considerations, data collection is still very much focused on the travel of economically active groups (Behrens et al., 2006).

It is never straightforward to collect income data in household surveys, in particular because of refusals to respond and the fact that the amounts involved are, deliberately or not, inaccurately reported. Researchers have investigated this issue in countries of the North (see, in particular Davern et al., 2005; Hansen and Kneale, 2013; Micklewright and Schnepf, 2010; Moore et al., 2000; Scott, 2003). In the case of travel surveys in countries like the United States or Australia, Stopher (2012) recommends asking respondents to indicate a relatively wide income band rather than state the exact amount in order to reduce nonresponse rates. The issue of collecting income data in surveys has, however, been considerably less studied in developing countries, even though the estimation of income poses particularly great problems there (Pettersen, 2005; Deaton, 1997; Deaton and Grosh, 2000). In theory, a more satisfactory approach would be to evaluate the standard of living on the basis of household expenditure (Deaton and Grosh, 2000), but the complexity and cost of a protocol of this type means that it cannot be implemented in a household travel survey (Diaz Olvera et al., 2008). The direct collection of individuals' incomes in these surveys is therefore indispensable. However, it raises three sets of difficulties, particularly in Africa.

First, several factors make it difficult to estimate the income derived from work. In this context where the amount of paid employment is falling and the number of informal microactivities is on the rise, many workers depend on precarious jobs and occasional work, for which they are paid irregular amounts at irregular times (De Vreyer and Roubaud, 2013). For the numerous self-employees, like petty traders or low-skilled craftpersons, it is difficult to estimate the net profit drawn from their activity as no accounts are kept. Similarly, in the case of young women, for example in apprenticeships, it is not at all easy to distinguish labour from domestic or nonremunerated activities. In addition, it is common for individuals to have a number of activities, and this applies not only to individuals in paid employment who do so in order to diversify their sources of income and to save, but also to individuals working in the informal sector, who do so in an attempt to compensate for the irregular nature of their principal activities (Bocquier et al., 2010; Ersado, 2006; Iyenda, 2005).

Second, income cannot be restricted to the sums that are earned from professional activities. It also includes grants and benefits, rents, pensions and, above all, gifts from one individual to 
another. Particularly in the case of the latter, it is difficult to estimate the sums involved because of the irregular nature of the transfers. But even if chains of solidarity are tending to weaken (Abdullah, 2000; Leimdorfer and Marie, 2003; Séraphin, 2000), gifts from outside the household continue to contribute significantly to the total income of individuals and households, particularly among the poor (Lourenço-Lindell, 2002).

Last, the economic behaviour of the population and the role of the household also add to the difficulty of estimating standards of living on the basis of income. Individuals are often unaware of the personal resources of the other members of their household, and not all income is pooled (Glick and Sahn, 2000; Hoddinott and Haddad, 1995; Posel, 2001; Yapi-Diahou, 2000). Among other things, the implication of this for transport is that access to motorised modes is more strongly conditioned by an individual's personal monetary resources than by those of his or her household (Diaz Olvera et al., 2008; Venter et al., 2007).

The aim of this paper is thus to evaluate in what way income data collection affects the accuracy of data and therefore the measurement of mobility inequalities. We have done this by referring to a household travel survey conducted in Douala (Cameroon) in 2003 in which respondents' income data was collected in a disaggregate and precise manner. The estimated values of mobility inequalities obtained from this survey have been compared with what was observed from less sophisticated data collection. This data was not the outcome of specific fieldwork conducted at the same time as the travel survey but was obtained from ex post simulations which provide less accurate income data, that are comparable with those obtained from surveys that collect income data in a much simpler way. The case study provides a variety of information about mobility inequalities in Douala. However, our aim is not to analyse their determinants or to identify policies that might reduce them, but rather to evaluate how their measurement is affected by a number of methodological decisions.

After a short description of the local context of Douala, Section 2 describes the income data collection procedure used for the travel survey and presents the simulation method. Section 3 uses the results of the simulations to show how the quality of income data affects the measurement of inequalities in daily travel and transport expenditure for individuals and households. Section 4 concludes on the benefits of detailed individualised income data collection for the measurement of inequalities in daily mobility and in transport expenditure. 


\section{DATA AND METHOD}

The PMU survey ("Pauvreté et Mobilité Urbaine”, Poverty and Urban Mobility) carried out in 2003 aimed to analyse the links between poverty, daily mobility and access to urban services in Douala ${ }^{1}$. Urban areas were stratified according to the availability of urban services, how long ago they became urbanised, distance from the centre and major roads, and the standard of living of the residents. Thirty survey zones were then selected within the stratified areas and the sample of households was selected randomly within the survey zones. 600 households and 1885 individuals of over 10 years of age were surveyed by face-to-face interviews in their home (Sitrass, 2004).

\subsection{The study zone}

Douala is Cameroon's most populous city, with nearly 2 million inhabitants in 2003. It is also a port and the main gateway for imports and exports. Douala is the country's economic capital and provides the location for more than half the country's economic activity and industrial production. Economic activity is nevertheless dominated by the informal sector which employed $62 \%$ of the workforce in 2005 . As a result of the low level of wages, $14 \%$ of the population have at least two professional activities (De Vreyer and Roubaud, 2013).

The city has developed in a site that is subject to severe geographical constraints. Some informal districts have sprung up in swampy zones or on natural drainage courses or slopes. The Wouri River which crosses the city also poses a major constraint for transport, since the only bridge between the two banks creates a notorious bottleneck (Figure 1).

\footnotetext{
${ }^{1}$ The PMU survey was carried out by a team composed of French and Cameroonian researchers, including the authors of this paper, who were responsible for the project's general methodology, in particular the survey questionnaire.
} 


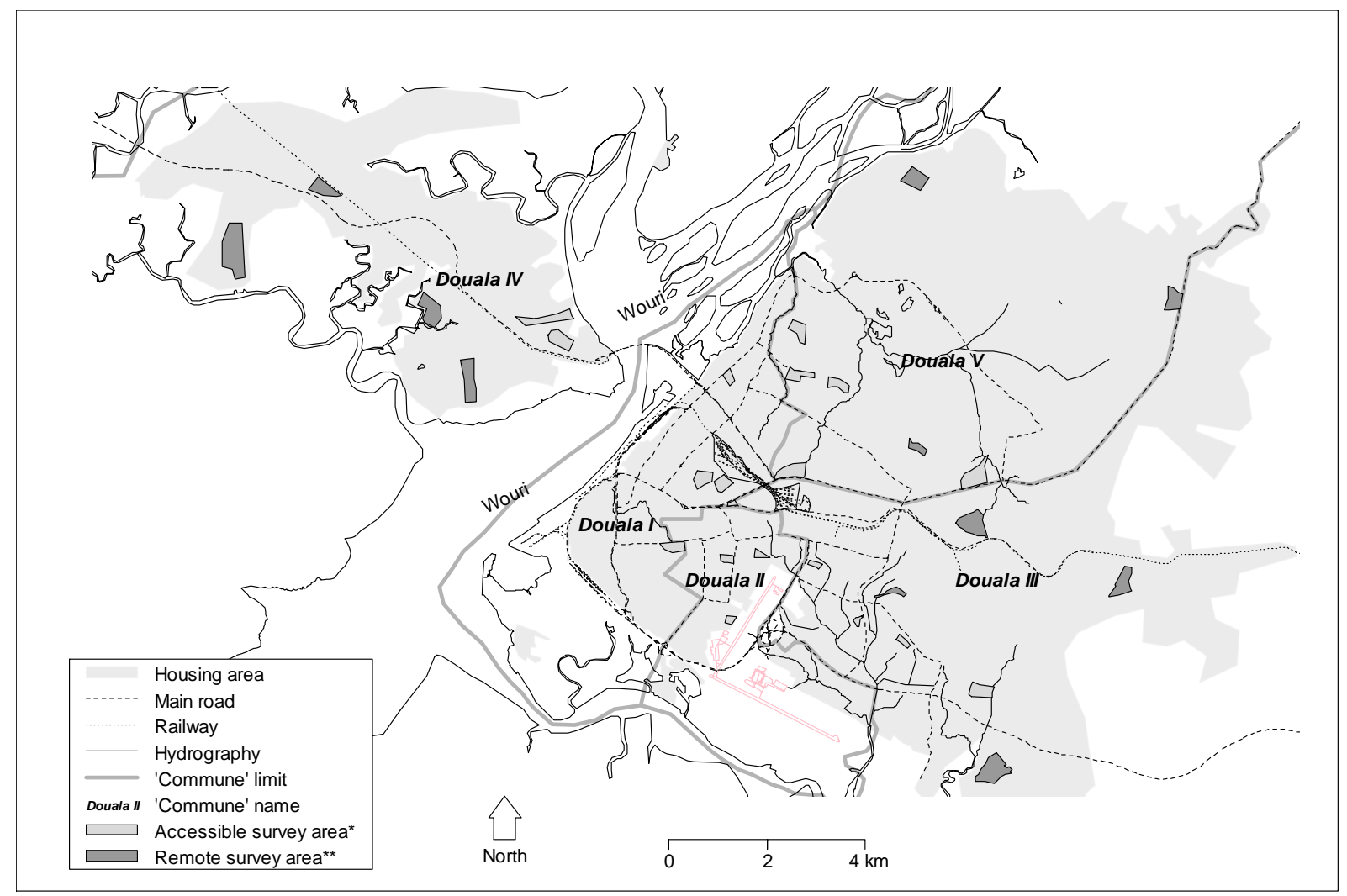

* The nearest public transport stop is less than 15 minutes away on foot

** The nearest public transport stop is 15 minutes or more away on foot

Fig. 1. The conurbation of Douala and the survey zones in the PMU household travel survey (2003)

As in other cities of sub-Saharan Africa, in Douala walking is still the population's principal means of transport. Access to private vehicles is very limited and motorised trips are mainly made on public transport (Diaz Olvera et al., 2013) which is provided by six modes: shared taxi, motorbike taxi, minibus, bus, light truck, undeclared cab. Most public transport trips are made by shared taxis, but the modal share of motorbike taxis is rapidly increasing, as they are less expensive over short distances and can provide a door-to-door service. The ease with which residents can access a public transport mode from their home varies according to the availability of roads and public transport in the district in which they live and access and egress segments made on foot may be long. Walking access and egress times allow us to identify which of the survey zones are accessible - when the place of residence is on average less than 15 minutes from the loading point -, and which zones are remote - when it is 15 minutes or more away ${ }^{2}$.

\footnotetext{
${ }^{2}$ This dichotomous spatial indicator is crude, due to a lack of exhaustive data about the districts' accessibility and facilities. It does not allow us to measure a gradient of increasing difficulty in access and only takes account of one dimension of the accessibility problem, namely access to public transport.
} 


\subsection{Capturing professional activities and income in the PMU Survey}

The PMU survey collected data at two levels. First, at the level of the household, the reference individual provided information on the composition of the household, the dwelling, and access to basic services and infrastructure. Second, each individual of over 10 years of age was interviewed personally, with the focus placed on his or her socio-economic characteristics, access to private vehicles, expenditure on transport and trips made on the day before the interview.

With regard to socio-economic characteristics, several sets of questions provided precise information about each individual's professional activities and income ${ }^{3}$. First of all, a set of questions allowed us to list each professional activity exercised by the respondent. Each individual was asked if he/she was currently engaged in a professional activity and if so:

1. the nature of the principal activity, its frequency (over the last 12 months and the last 30 days) and for how long the individual had been doing it (Figure 2). This information allowed us to calculate annual incomes;

2. the description of any remunerated secondary activities (Figure 3). A secondary activity is defined as a supplementary professional activity practiced by an individual currently in employment (i.e. in the past 30 days) ${ }^{4}$.

\begin{tabular}{|l|l|}
\hline No. & Question \\
\hline 29. & $\begin{array}{l}\text { Have you been gainfully employed (in cash or in kind) in the } \\
\text { past } 30 \text { days? }\end{array}$ \\
\hline 30. & Is this a permanent job? \\
31. & Are you a salaried employee? \\
33. & Description of principal activity \\
\hline 39. & For how long have you been engaged in this activity? (number \\
& of years) \\
40. & How many months did you work out of the past 12 months? \\
41. & How many days did you work out of the past 30 days? \\
\hline
\end{tabular}

Fig. 2. Identification of principal activity in the PMU survey

\footnotetext{
${ }^{3}$ By interviewing each respondent it is possible to overcome biases which result from the use of a single informant for an entire household (Fisher et al., 2010). Insofar as the reference individual is not necessarily correctly informed about the situation of each household member, it would appear to be questionable to rely only on his or her statements.

${ }^{4}$ The level of multiple activities measured by the PMU survey was $12 \%$, which is close to the value obtained by De Vreyer and Roubaud (2013).
} 


\begin{tabular}{|l|l|}
\hline No. & Question \\
\hline 36. & $\begin{array}{l}\text { Do you have other activities that generate income in cash or } \\
\text { in kind? }\end{array}$ \\
\hline 37. & How many? \\
\hline 38. & What are these activities? \\
\hline
\end{tabular}

Fig. 3. Identification of secondary professional activities in the PMU survey

With regard to income, our aim was to assess as accurately as possible the individual's total monetary resources, by mentioning a variety of potential sources, which may or may not be linked to professional activities (Figure 4). Respondents were left free to estimate their earnings from each source according to the most appropriate periodicity. There are two advantages to this more detailed data collection procedure:

- As an individual can have several sources of income, listing them during the interview helps to reduce omissions;

- Whatever the periodicity reported by the respondent, each type of income can be extrapolated on a monthly or annual basis in order to estimate a total sum.

In this paper, we have harmonised the separate incomes to express them in monthly terms, then consolidated them for each individual; the sum of individual incomes has been used to estimate the household's total income.

The survey protocol makes it very clear that the income data should relate to money earned outside the household in order to avoid double counting. In particular this prevents the counting of monetary transfers between members of the household (pocket money, paying for meals taken outside the household). Particular attention was paid to the collection of income data during the training of field staff in order to make them aware about variable periodicities, the difference between turnover and profit and the need to avoid double counting if several members of the household take part in the same economic activity. 


\begin{tabular}{|c|c|c|c|c|}
\hline No. & Type of monetary resources ( $C F A$ francs) & $\begin{array}{l}\text { Do you } \\
\text { receive... } \\
\text { 1. Yes } \\
\text { 2. No }\end{array}$ & $\begin{array}{l}\text { Periodicity } \\
\text { 1. Daily } \\
\text { 2. Weekly } \\
\text { 3. Monthly } \\
\text { 4. Quarterly } \\
\text { 5. Half-yearly } \\
\text { 6. Annually } \\
\text { 7. Other.......... }\end{array}$ & Amount \\
\hline & $\begin{array}{l}\text { Wages / salary / profit from principal } \\
\text { activity }\end{array}$ & & & \\
\hline & $\begin{array}{l}\text { Wages / salary / profit from secondary } \\
\text { activity (activities) }\end{array}$ & & & \\
\hline & $\begin{array}{l}\text { Wages / salary / profit from other } \\
\text { professional activities }\end{array}$ & & & \\
\hline 54. & Total labour income $(51+52+53)$ & & & \\
\hline 55. & Annuities & & & \\
\hline & $\begin{array}{l}\text { Grants, gifts, alimony, allowances, etc. } \\
\text { (from persons outside household) }\end{array}$ & & & \\
\hline 57. & Family allowances, pensions, scholarships & & & \\
\hline 58. & Other & & & \\
\hline 59. & Total other income $(55+56+57+58)$ & & & \\
\hline 60. & Total individual income $(54+59)$ & & & \\
\hline
\end{tabular}

Fig. 4. The collection of individual income data in the PMU survey

\subsection{The evaluation of income data in the PMU survey}

It is possible to compare the sources of income that were collected in the PMU survey with those collected during a survey that dates from 2002, namely the CAVIE survey (INS, 2003). This survey collected information on the living conditions of 7500 households: infrastructure and basic services, services in the dwelling, durable goods. Household composition and information on all members of the household were also included in the survey.

Two major methodological differences with the PMU should be noted:

- a single informant was questioned in each household in order to provide not only general information about the household, but also specific information on each individual;

- the single informant was asked whether each member of the household had worked in the last twelve months (and if so in which sector), about his/her main sources of income and the sums involved, broken down into two categories, professional and other. These two amounts were expressed as a bracket. 
As a result of these methodological differences, the distribution of individuals (of over 10 years of age) according to the principle source of income differs considerably between the two surveys (see the second and third columns of Table 1). While the CAVIE survey reports that one in two individuals had no income, the PMU survey gave a ratio of one in four. The differences were moderate when we compared the proportions of individuals whose work was their principal source of income, but the PMU survey reported a higher proportion of individuals receiving pensions or rents and, in particular, receiving mainly gifts. This is because the information relating to the individual was collected directly from him/her and also because these sources of income were identified specifically in the questionnaire (Questions 55 to 58, Figure 4). The sums involved were often small, particularly in the case of gifts ${ }^{5}$. Nevertheless, these gifts from outside the household were frequently the only source of income for schoolchildren and the economically inactive.

\section{Table 1}

Distribution of individuals according to their principal source of income and probabilities used to simulate income distributions for the PMU survey sample

\begin{tabular}{|c|c|c|c|}
\hline & $\begin{array}{l}\text { PMU survey } \\
(\%) \\
\text { (a) }\end{array}$ & $\begin{array}{l}\text { CAVIE survey } \\
(\%) \\
\text { (b) }\end{array}$ & $\begin{array}{c}\text { Relative } \\
\text { disparity } \\
(a-b) / a\end{array}$ \\
\hline Individuals with an income & 74.5 & 48.5 & \\
\hline Professional activities & 49.4 & 43.8 & 0.114 \\
\hline Allowances, rent or other & 4.5 & 2.0 & 0.559 \\
\hline Gifts & 20.6 & 2.7 & 0.869 \\
\hline Individuals with no income & 25.5 & 51.5 & \\
\hline Total & 100.0 & 100.0 & \\
\hline
\end{tabular}

\subsection{Measuring mobility inequalities, simulating degraded data collection}

Mobility practices were measured using two categories of indicators:

- Physical indicators, which were measured at the individual level, are the number of trips (total and motorised) and the travel time budget (total and motorised).

- Monetary indicators were estimated for individuals and for households. In both cases, the monthly expenditures on urban transport, for all modes and solely for public transport

\footnotetext{
${ }^{5}$ These gifts accounted for less than $10 \%$ of all the income reported in PMU survey. They accounted, of course, for an even smaller proportion according to the CAVIE survey, but it is impossible to calculate the exact percentage as income data was only recorded in the form of a bracket.
} 
modes, were computed ${ }^{6}$. The proportion of household income spent on urban transport was also calculated.

Inequalities have been evaluated using concentration curves and concentration indices (O'Donnell et al., 2008). The concentration curve provides a graphic representation of the proportionality of the distribution of an indicator (number of daily trips, travel time budget, transport expenditure) in relation to the population (individuals or households), which is ranked according to increasing income. It plots the cumulative percentage of a mobility indicator ( $y$ axis) against the cumulative percentage of the population, ranked from the poorest to the richest (x-axis). If the indicator is distributed among the population in a perfectly equal manner, any group's share of the indicator will be exactly equal to its relative size in the population. In this case, the cumulative percentages of both the indicator and the population will be exactly equal whatever population segment is considered. Graphically, the closer the plot is to the line of equal distribution (the first diagonal), the more equally the indicator is distributed among the population and the lower its concentration index. Mathematically, the latter is equal to 1 minus twice the surface area between the plot and the abscissa.

In order to produce a concentration curve or index it is therefore necessary to be able to class the population of individuals or households according to their standard of living. In the case of individual mobility indicators, the individual's income provides a better idea of his/her ability to access motorised modes than the income of the household (Diaz Olvera et al., 2008) and therefore allows us to estimate the individual's standard of living. In the case of household indicators, ranking households according to their total income means that a given income provides the same standard of living to an individual living alone, a couple, or a family with several children. In order to make the conversion from income to standard of living, economists use an equivalence scale that expresses the differing needs of different individuals (adults and children in particular) and the economies of scale that result from household size (e.g. a couple does not necessarily need twice the amount of space in their home as a single person). Determining an equivalence scale is however a complex problem that has raised much controversy (Lechêne, 1993). In the absence of a consensus, we adopt what Deaton and Zaidi have termed the "arbitrary method" (2002:51) which involves, in the case of poor countries, considering a low cost for a child and a low economy of scale coefficient, in our case

\footnotetext{
${ }^{6}$ To collect information on public transport expenditure, individuals were asked how many times they used each of the six modes of public transport and the corresponding amount spent during the past seven days. In motorised households, the running costs of vehicles were collected on a monthly basis (fuel) or annually (maintenance, repairs, insurance, licensing).
} 
respectively 0.25 and 0.10 . The number of individuals in the household is thus replaced by a number of consumption units which is equal to:

$$
(\mathrm{A}+\alpha \cdot \mathrm{K})^{(1-\beta)}
$$

where $\mathrm{A}$ is the number of adults, $\mathrm{K}$ the number of children, $\alpha=0.25$ and $\beta=0.10$. The standard of living of the household is then estimated on the basis of the total household income divided by the number of consumption units. Finally households are ranked according to these estimated standards of living.

This methodological basis allows us to calculate mobility inequality indicators, when an estimate of individual incomes is available. An additional stage is necessary in order to assess how the precision of income data collection affects the measured mobility inequalities. This consists of comparing the observed value of the indicator with that which would have been obtained if the distribution of individuals according to their principal source of income had been the same in the PMU and CAVIE surveys. We are, of course, unable to observe this situation. However, we can use the available data to simulate it.

The simulation method can be summarised as follows. The distribution of individuals on the basis of their principal source of income as reported in the CAVIE survey, which identified more individuals without incomes, was applied to the sample from the PMU survey, which meant that randomly selected respondents had their incomes reset to zero. The proportion of such individuals with their incomes reset to zero depends on the nature of their principal source of income (see last column in Table 1). It was $11.4 \%$ when the principal source of income was labour, i.e. approximately one in nine individuals in this category, 55.9\% when it consisted of allowances, rents or other sources and $86.9 \%$ when gifts were the principal source of income. In each simulation the distribution of individuals according to their principal source of income was therefore equivalent to that obtained from the CAVIE survey ${ }^{7}$.

To correct for the random nature of resetting the income of one individual to zero rather than another, we carried out a large number of simulations in order to estimate the stability of the

\footnotetext{
7 This simulation strategy allows us to simulate "realistic" populations. In the simulations, each individual's mobility is accurately estimated, but the individuals (and therefore the households) are incorrectly classified because the data on their income is incorrect. The error in the estimation of inequality is therefore due to the combination of two sources of error: an erroneous classification of individuals and an erroneous estimation of mobility for a given income level. This simulation method was preferred to one which involves directly duplicating the individuals that are already present in each principal income source category until a distribution similar to that in the CAVIE survey is obtained. This is because an alternative strategy of this type would accurately estimate mobility for each income level thereby eliminating a potential source of error in the inequality calculation.
} 
mobility inequality measures. For each inequality measurement, the value observed in the PMU survey can be compared to the median of the simulated values, as well as to the amplitude of the distribution of the simulated values ${ }^{8}$. We thus determined, for each inequality measurement, the number of simulations that is required in order for the estimates of the median value and the amplitude to become stable. This number varied slightly depending on the inequality measurement in question, but never exceeded 500. The results presented below are therefore based on a unique set of 500 simulations.

\section{IMPACTS OF THE INCOME DATA COLLECTION METHOD ON THE MEASUREMENT OF MOBILITY INEQUALITIES}

We shall begin by considering the physical indicators of mobility, then move on to the monetary indicators. For a given mobility indicator, if the observed value of the inequality measurement and the median simulated value are close together and the dispersion of the simulated values is small, the income data collection method has little impact on the mobility indicator. If there is a large disparity between the two values, particularly if the observed value is outside the range of the simulated values, it means that our perception of the inequalities is biased when the income data is collected in a simplified manner.

\subsection{Inequalities according to physical indicators}

The total number of trips and the daily travel time budget are the indicators that are the most equally distributed according to the income of individuals. As shown by Figure 5, they are also those for which the impact of a precise measure of income is the most limited: the median of the simulated values is indistinguishable from the observed value and the range of the simulated values is very narrow. Differences for these mobility indicators according to income tend to diminish because citizens with low income or no income at all compensate for their lower access to motorised modes by intensive walking. This explains why the values of the corresponding concentration indices are close to zero ${ }^{9}$.

\footnotetext{
${ }^{8}$ The central tendency parameter of the distribution of the inequality indicators calculated from the simulated incomes is the median rather than the mean value, due to the risk of extreme values appearing in the case of some simulations. For the same reason, when the amplitude of the distribution of the inequality indicators was estimated, the $2.5 \%$ of extreme values at the bottom and the top of the distribution were excluded.

${ }^{9}$ As the concentration plots for the number of trips and the travel time budget for all modes are almost flat and indistinguishable from the first diagonal, they are not shown here.
} 


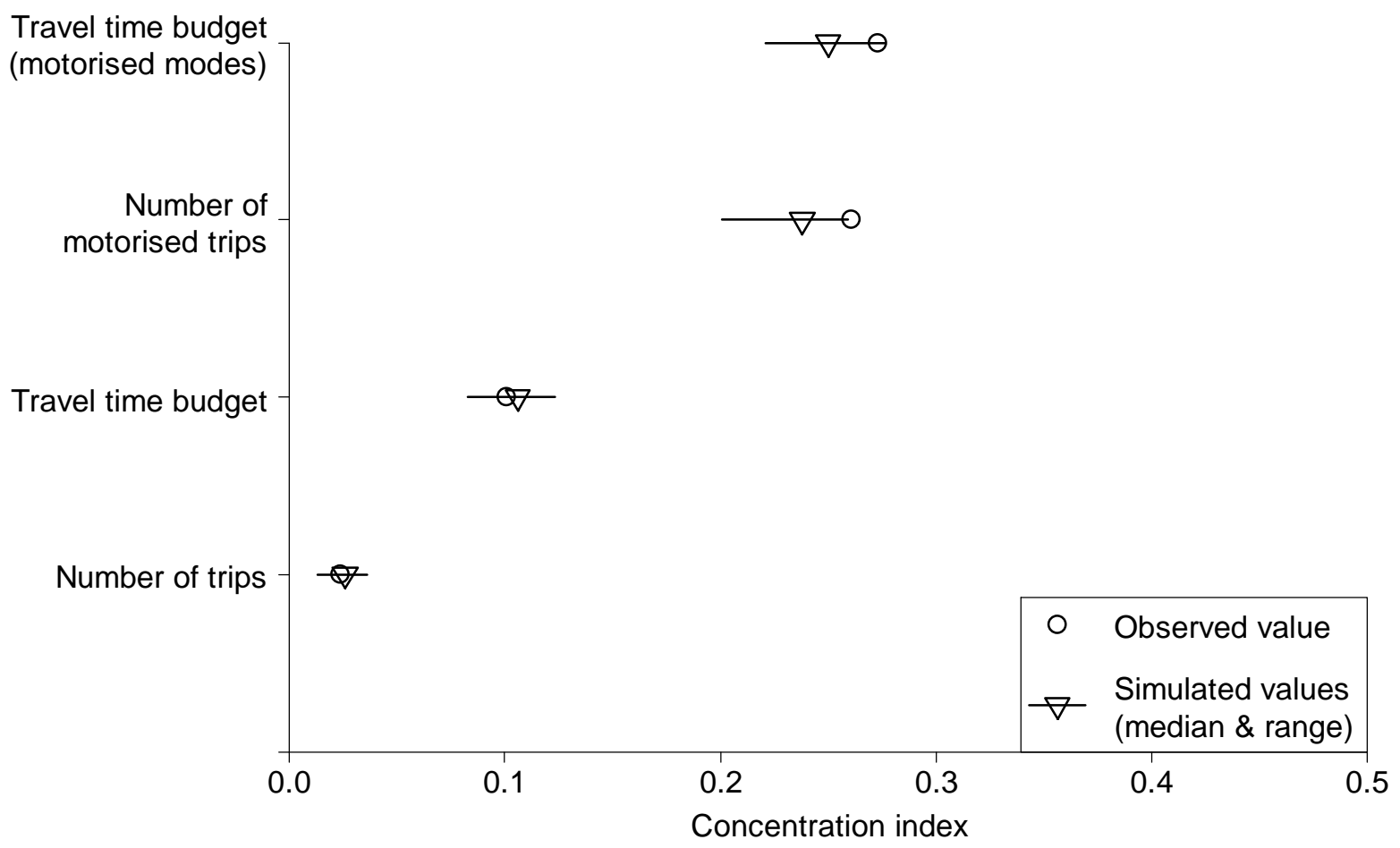

Fig. 5. Observed and simulated concentration indices for number of trips and travel time budget (all modes and motorised modes)

The benefits of collecting accurate income data increase when the travel indicators are limited to motorised modes. As can be seen in Figures 6 and 7, the plots for the simulated income distributions are above the plot for the observed distribution ${ }^{10}$ and the largest differences between curves are concentrated in the bottom half of the distribution. This means that collecting aggregated data reduces inequalities with regard to motorised travel. With regard to the concentration indices (not shown here), the observed value is at best indistinguishable from the upper bound of the range of simulated values and at worst above this bound. The simulated concentration indices are about $90 \%$ of those obtained for the observed data. It is important to note that this underestimate does not affect the entire population in the same way and is essentially due to an inaccurate evaluation of the situation regarding the poorest half the population, as shown by the concentration curves.

\footnotetext{
${ }^{10}$ In order to improve the comprehensibility of the figures and facilitate their interpretation, only six curves have been plotted for each: that obtained directly from the PMU survey and five simulations randomly chosen from amongst the five hundred.
} 


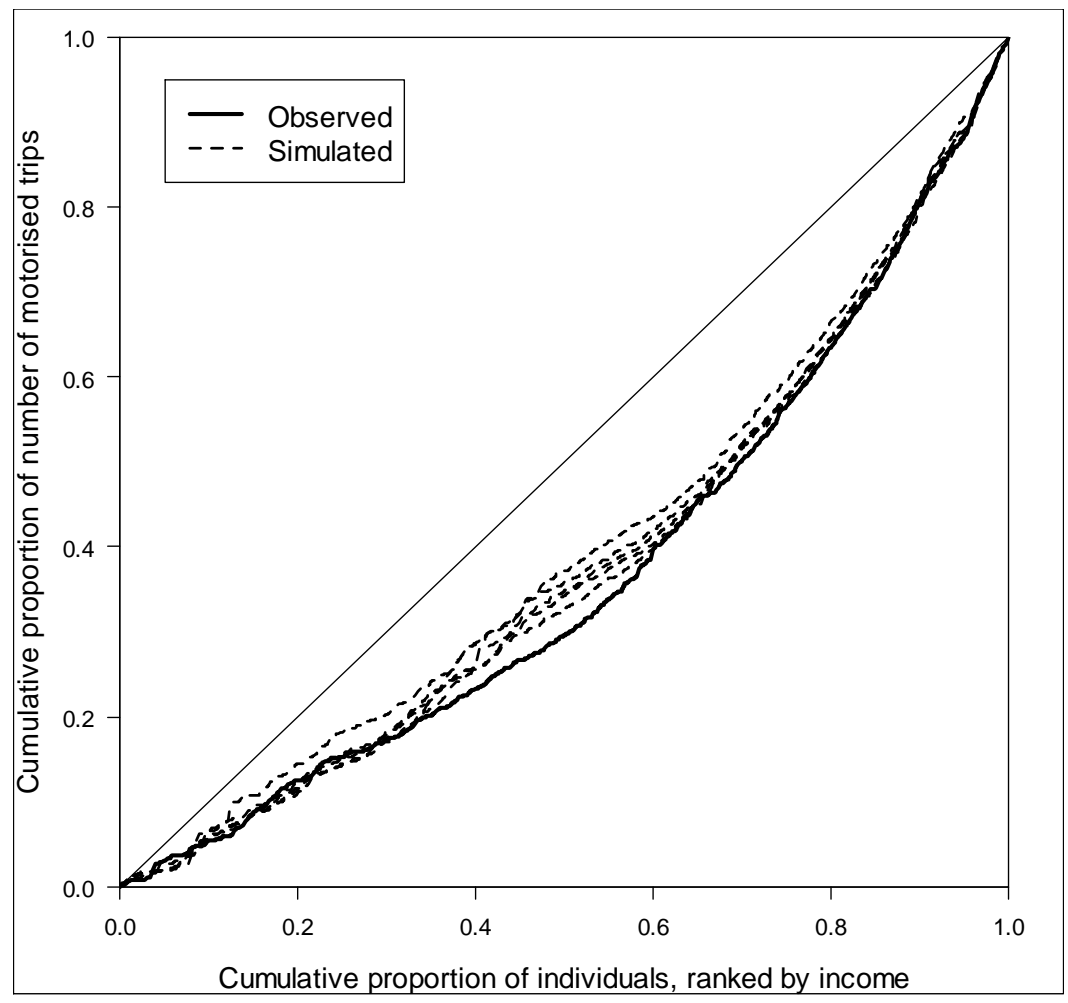

Fig. 6. Concentration curves for number of motorised trips: observed distribution and five simulated distributions of individual income

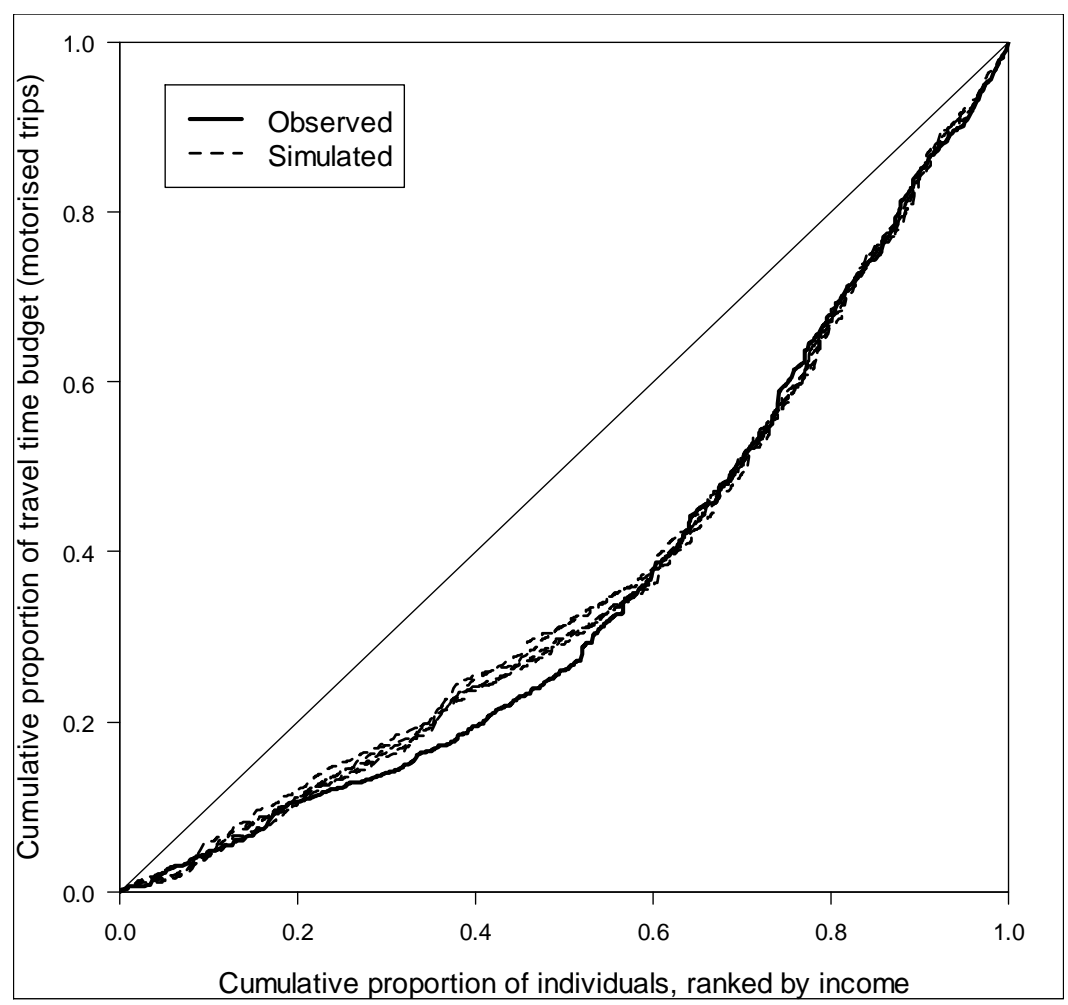

Fig. 7. Concentration curves for motorised travel time budget: observed distribution and five simulated distributions of individual income 
If we take account of the residential location of the individual's household, distortions in our representation of spatial inequalities become apparent. Once again, the effects are rather negligible in the case of the indicators for all modes (Figure 8). However, use of motorised modes, which is more unequally distributed within remote zones, is more inaccurately measured when income data collection is simplified. For these districts, the observed inequality is greater than the simulated values while it is near the median of the simulated values for the accessible zones. Moreover, the range of simulated values is very large in the case of the remote zones and leads to a partial superimposition of the distributions of simulated values for the two types of zones. Consequently, in between $1 \%$ (number of motorised trips) and $2 \%$ (motorised travel time budget) of simulations, inequality is greater in the accessible zones than in the remote zones, while the observed concentration index is greater in the remote zones than in the accessible zones by almost half. Excessively aggregated collection of income data may therefore lead to an underestimation of inequalities in each type of zone, and sometimes to a false impression of the relative situation in the two types of zone.

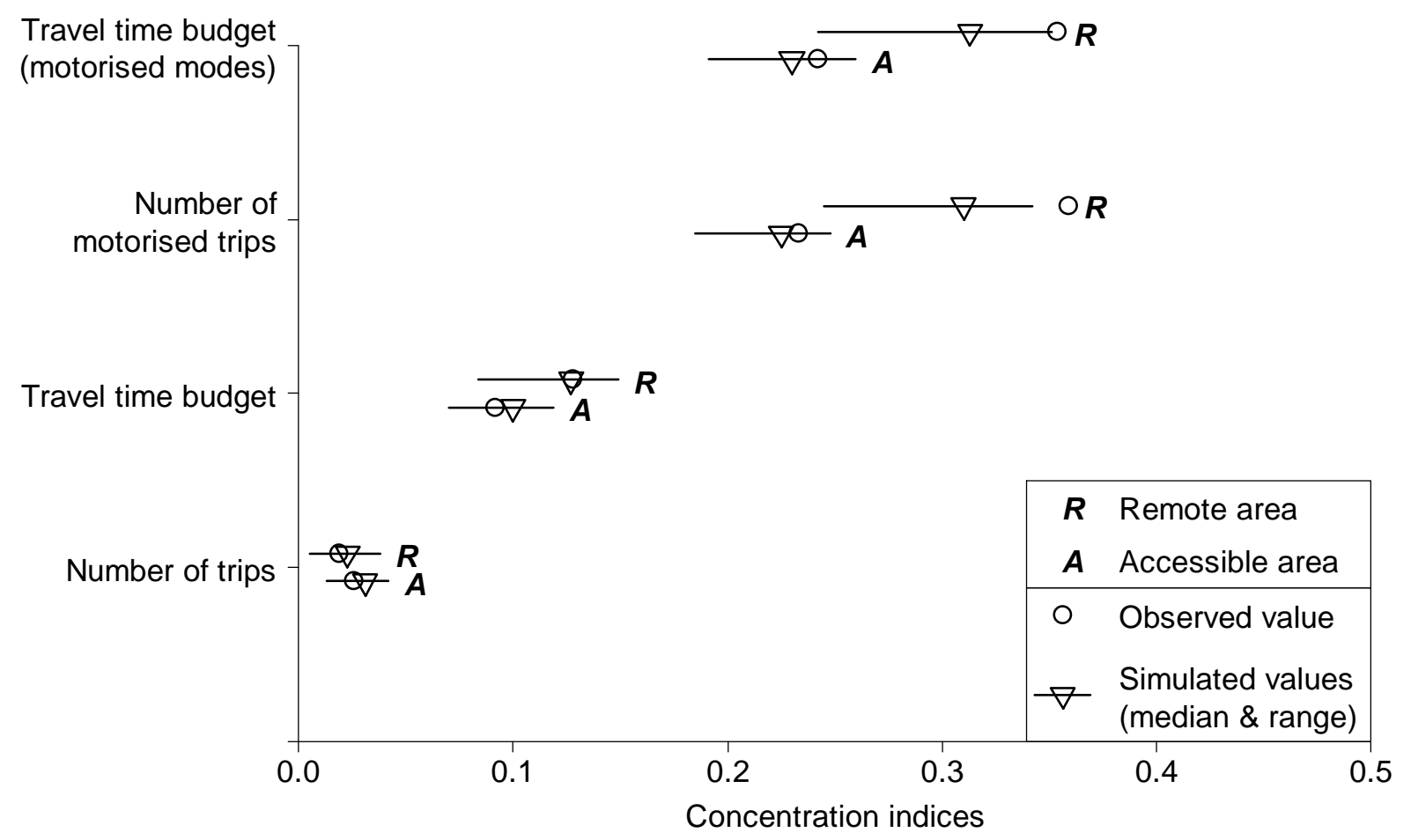

Fig. 8. Observed and simulated concentration indices for number of trips and travel time budget (all modes and motorised modes), according to type of residential zone 


\subsection{Inequalities according to monetary indicators}

The benefit of the precise estimation of incomes is even clearer when we consider the concentration of individuals' travel expenditure (Figures 9 and 10). Once again, almost all the simulated plots are above the observed plot throughout the distribution. The differences are particularly marked for the bottom half of the distribution. The result is a significant underestimate of the inequalities as the concentration indices for the simulated values only attain $85 \%$ of those for the source data.

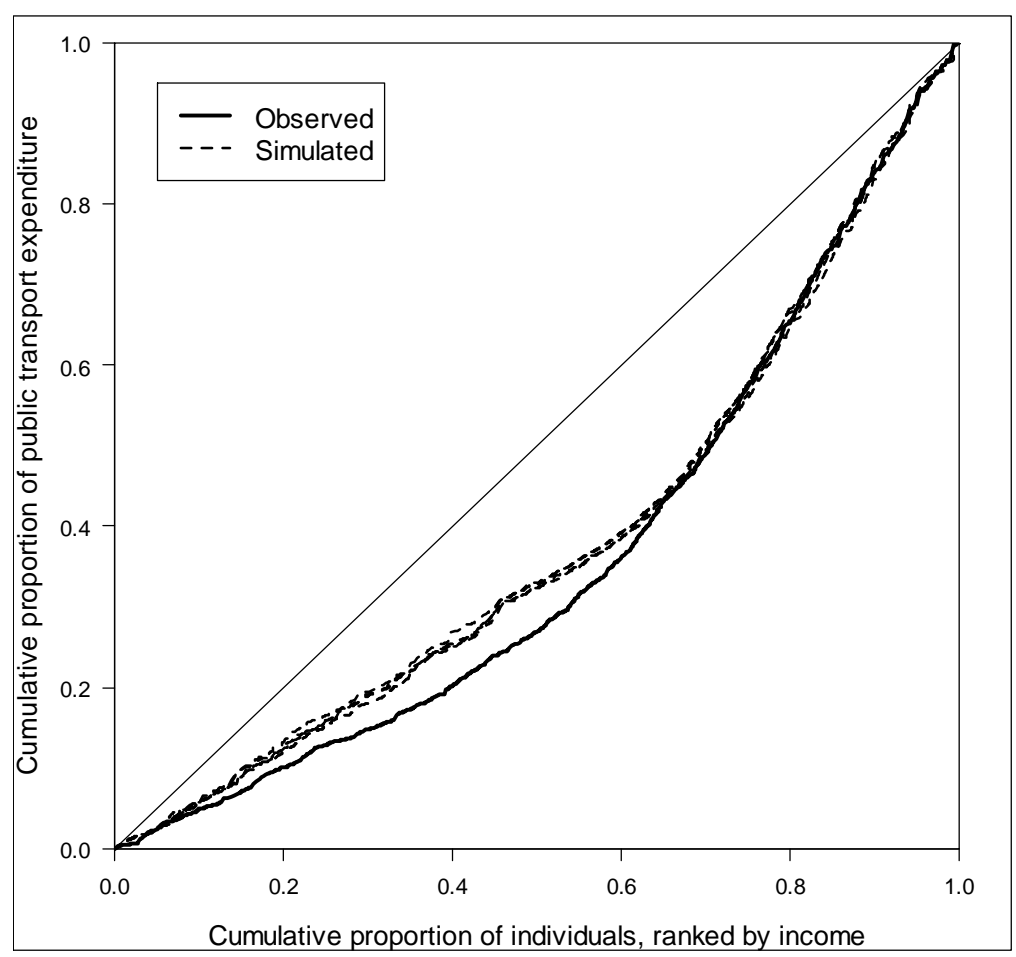

Fig. 9. Concentration curves for public transport expenditure: observed distribution and five simulated distributions of individual income 


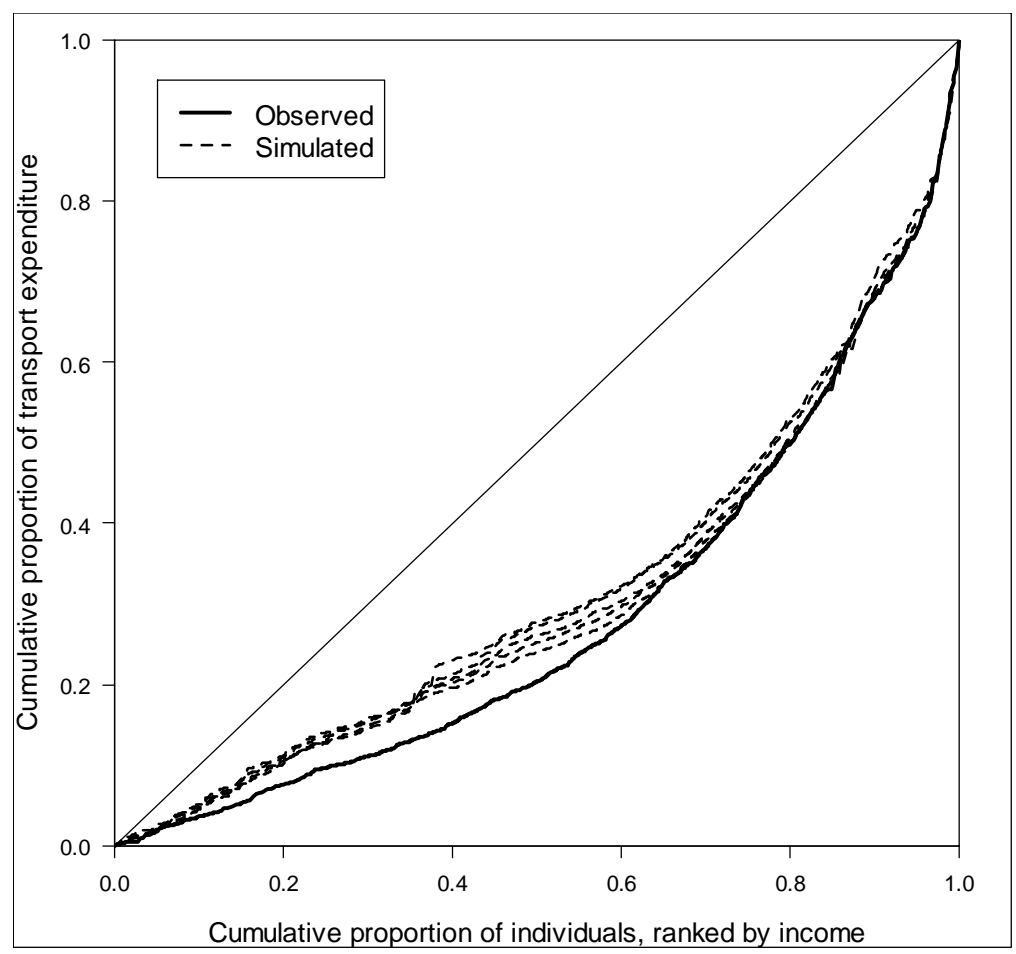

Fig. 10. Concentration curves for total transport expenditure: observed distribution and five simulated distributions of individual income

Household analysis considerably reduces the estimated value of inequality and the variability between observed and simulated data (Figure 11). This is caused by aggregating in the same unit (the household) individuals with heterogeneous characteristics, for example economically active husbands with a large income and wives or young non-working individuals with a low income. The simulated concentration indices nevertheless remain lower than the reference indices (by approximately 11\%), but the errors due to incomplete collection of income data are slightly displaced in relation to the plots for individuals. The concentration plots (not shown here) reveal that these errors are uniformly distributed, except at the top of the distribution.

As in the case of the physical mobility indicators, inequalities in mobility expenditure are less accurately measured in the case of the residents of remote zones (Figure 12). In addition, the simulated values exhibit a high degree of superimposition (individual expenditure on public transport) or complete superimposition (the other three expenditure indicators). This superimposition has little impact on the household level indicators, for which the observed values do not differ markedly according to the type of district. Its effects are greater in the case of the individual indicators. In $2.5 \%$ of the simulations of individual expenditure on public transport and $16 \%$ of the simulations of overall transport expenditure, inequality seems greater 
in the accessible zones than in the remote zones, while the coefficients of concentration clearly show the opposite.

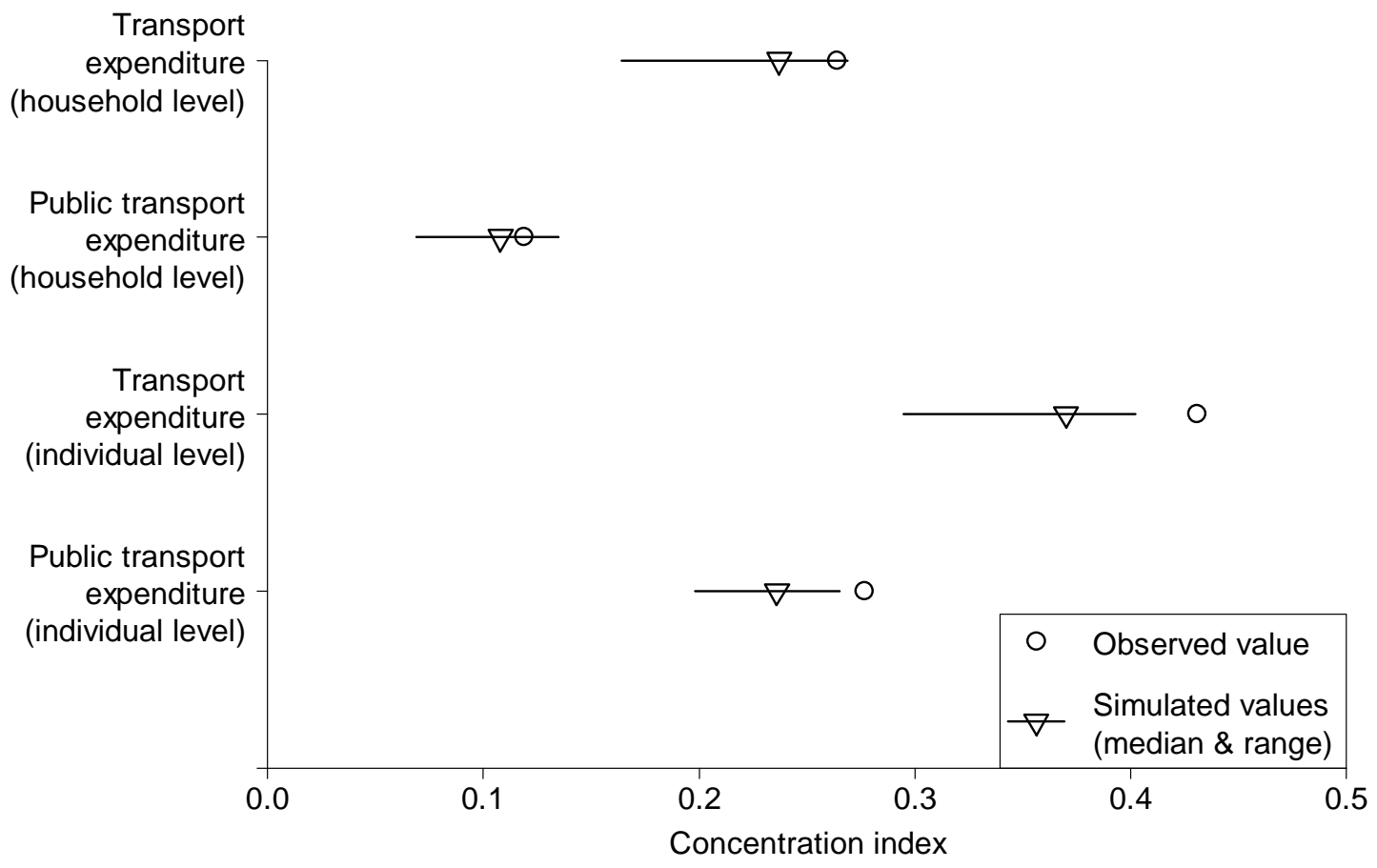

Fig. 11. Observed and simulated concentration indices for individual and household transport expenditure

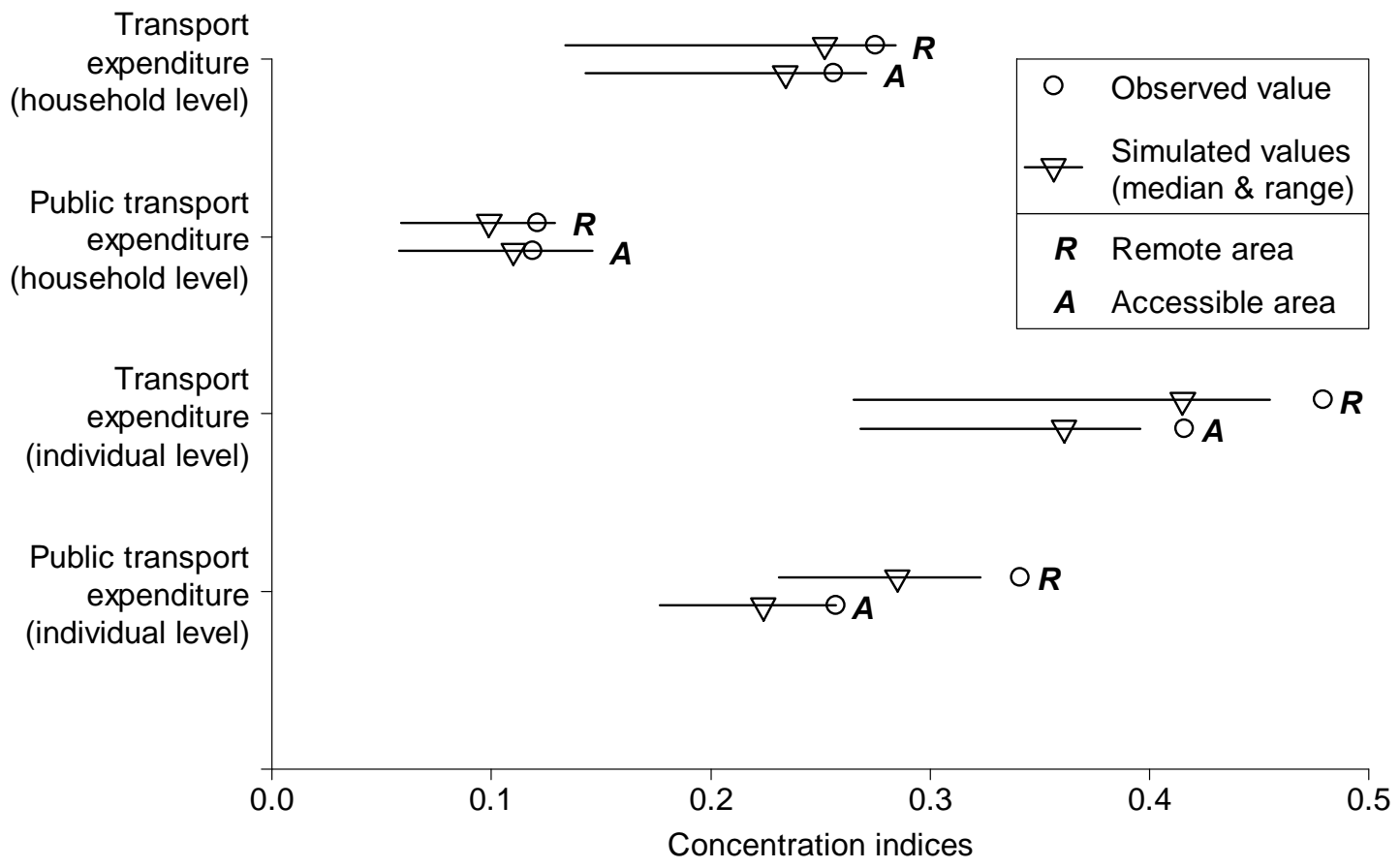

Fig. 12. Observed and simulated concentration indices for individual and household transport expenditure, according to type of residential zone 
Households spend on average $17 \%$ of their budget on daily travel, but this proportion varies according to their standard of living. As can be seen in Figure 13, transport accounts for a lower share of expenditure as households become more well-to-do. According to the observed values, daily travel absorbs almost a quarter of the resources of the poorest households (first quartile), a fifth of those in the second quartile and about a seventh of those in the most well-to-do half of the population (quartiles 3 and 4). The simulated distributions also show a tendency for the budgetary coefficient to fall as household resources increase. But the estimated coefficients are in this case systematically greater than those that have been observed, the bias once again varying greatly according to the wealth of the household. The situation of the more well-to-do is accurately represented, but there is an overestimation of $4 \%$ for the two intermediate quintiles and of approximately $50 \%$ of the total income in the case of the poorest households. In the case of this last group, the coefficients obtained from the simulations are clearly totally unrealistic. Such high values would mean that households would then have only a very small proportion of their income left to live on (food, housing, education, clothes, etc.).

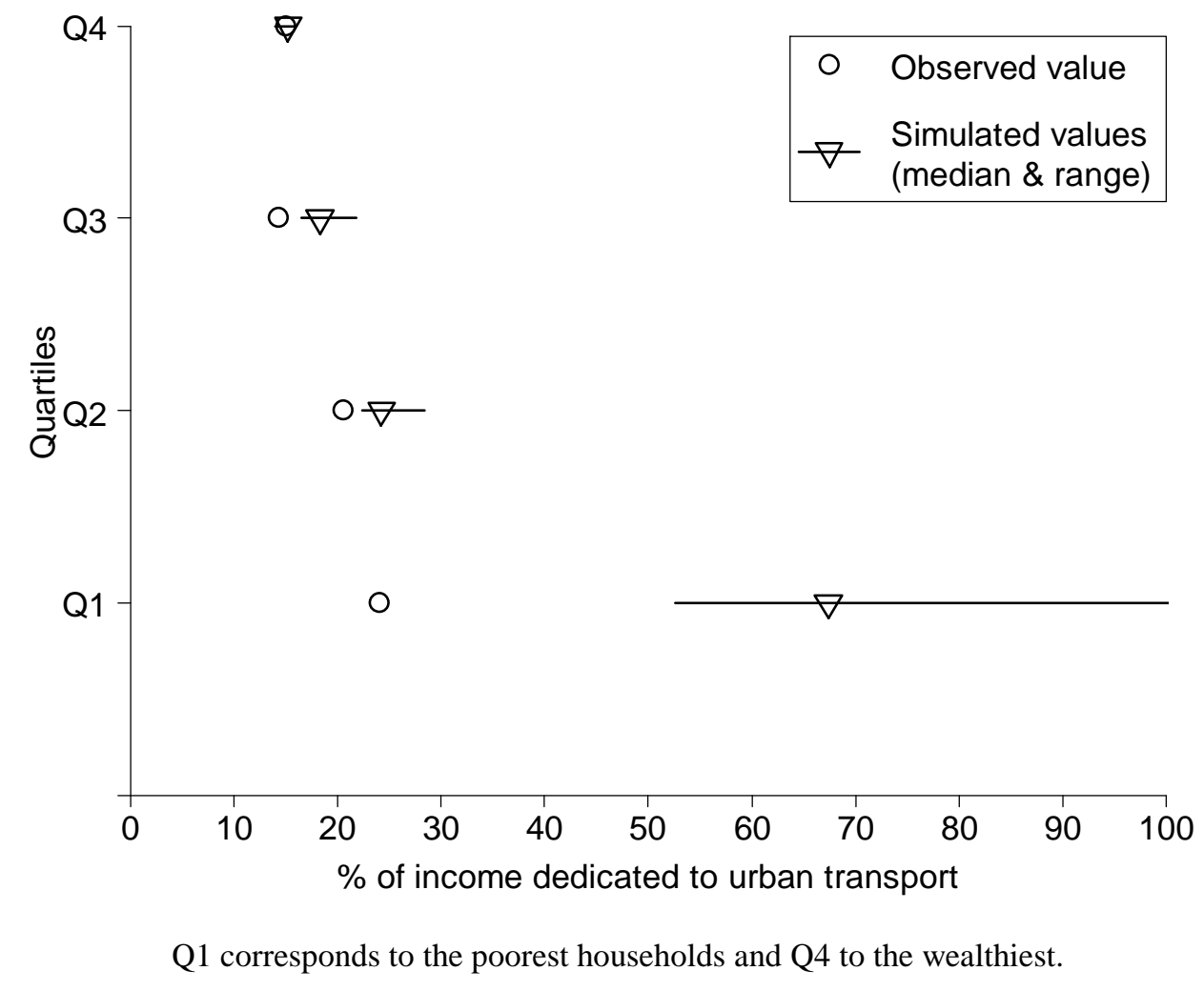

Fig. 13. Proportion of household income devoted to daily mobility, according to income quartile 
By taking account of residential location we can observe similar trends: there is a deterioration in the quality of the estimation from the wealthy to the poor which leads to unrealistic estimations for the first quartile whatever the type of zone (Figure 14). There is also a relative inversion of the position of the two types of area for the poorest half of the population. Once again, incomplete or inaccurate income data collection leads to an erroneous estimate of the budgetary coefficient of transport, in particular for the poorest households.

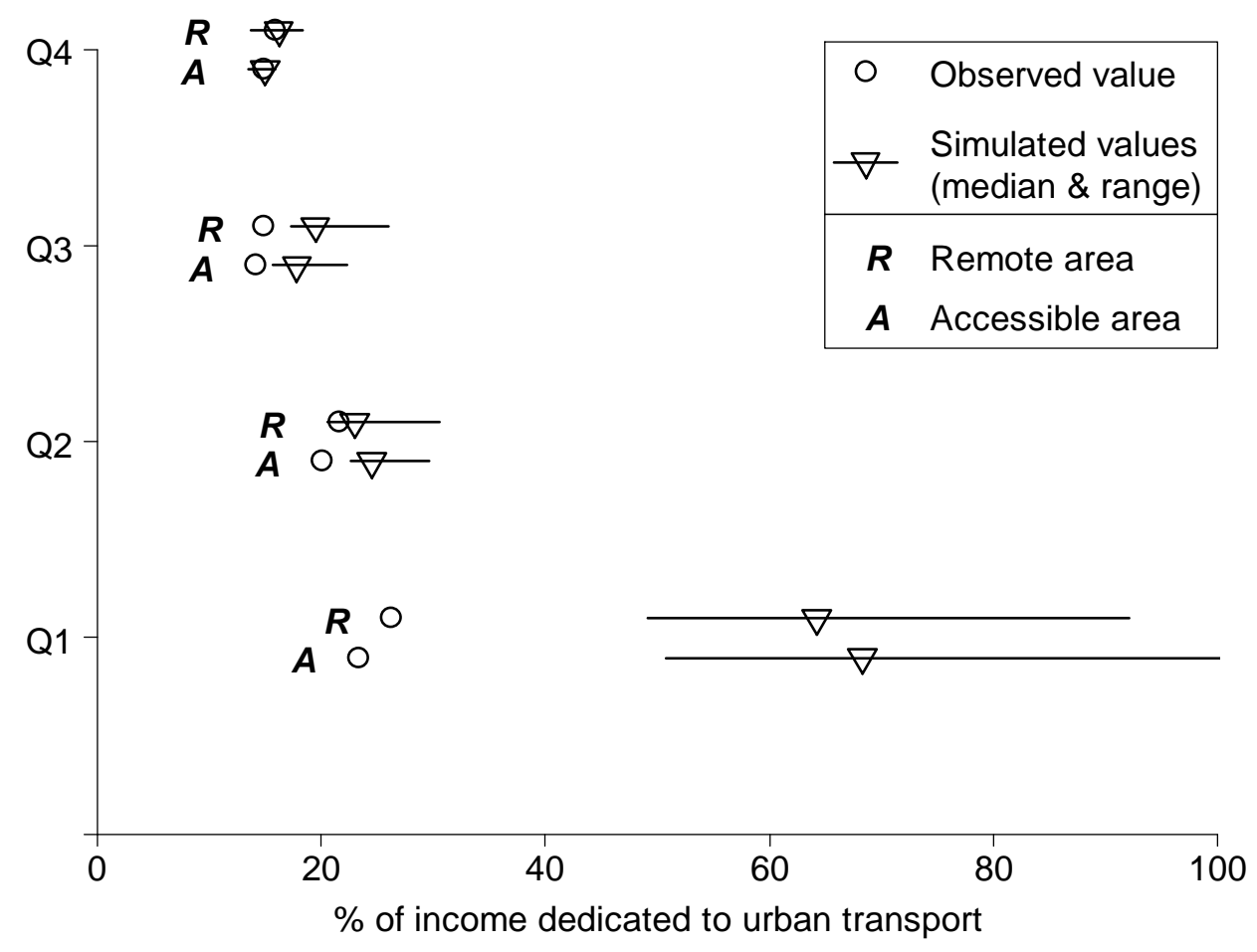

Q1 corresponds to the poorest households and Q4 to the wealthiest.

Fig. 14. Proportion of household income devoted to daily mobility, according to income quartile and type of residential zone

\section{CONCLUSION}

The income data collection method used in the PMU survey removes the majority of the difficulties that were mentioned in the introduction:

- the detailed listing of professional activities of whatever nature and scale makes it easier subsequently to collect more reliable data on income from work;

- the explicit mentioning of a variety of sources of income (gifts, pensions, rents, etc.) considerably increases the reported sums; 
- allowing the respondent to select the periodicity with which he or she reports income brings the situation described in the survey closer to real practices;

- conducting a specific interview for each individual avoids the need to rely on a single informant who may not be very well aware of the situations of individual household members.

However, the methodology that we have chosen does not allow us to perceive the scale of the pooling of individual income within the household, but the opening of the "black box" of the household (Alderman et al., 1995:15) remains a theoretical and empirical problem.

Of course, these options are expensive in terms of both respondent burden and survey cost. But our analyses have shown that more precise data collection improves the estimation of mobility inequalities. Indeed, the data collection method has a direct impact on the ranking of individuals and households in terms of standard of living. In turn, the ranking of individuals and households has impacts on the measurement of inequalities as regards mobility and transport expenditure. Our analysis shows that the effect of more accurate income data is minor in the case of aggregated indicators (e.g. overall number of trips, travel time budget for all modes, or household level indicators) and for the most affluent groups (individuals and households). On the contrary, the most significant impacts concern disaggregated indicators (e.g. number of motorised trips, motorised travel time budget or individual level indicators). But when there is an effect, it is systematically in the same direction. Simplified data collection tends to minimise the scale of inequalities and the error is greater in remote zones than in accessible zones. This differentiated effect is absolutely clear, in spite of the limitations of our spatial indicator. It is also to some degree independent of the effect of the household's standard of living. Finally, the errors in the ranking of households lead to estimate, in the case of the poorest households, very high and therefore improbable proportions of household income spent on transport.

Shortcomings in the methodological apparatus blur our perception of the social and spatial situation of underprivileged groups and distort our assessment of mobility inequalities. Ultimately, they impede investigation of the links between daily travel, poverty and social exclusion. It seems essential to improve the way income data is collected in surveys in order to obtain a more accurate picture of the mobility inequalities linked to households' and individuals' standards of living and their residential location.

This need applies beyond the case of Douala. Making similar comparisons to those presented here in other urban contexts, in other African countries, or even in other developing or 
developed regions, would allow us to evaluate the extent to which the lessons we have learned from Douala can be generalised. Nevertheless, similar effects to those we have revealed in Douala are likely to pertain to other African cities. The reason for this is that large African cities share a considerable number of features: the jobs market is dominated by the informal economy, there are large inequalities with regard to income and widespread poverty, rapid spatial expansion, a lack of basic facilities, low private vehicle ownership rates and a public transport system which is informal, inefficient and unsubsidised. In situations of this type it is particularly important to be able to evaluate accurately the redistributive nature of urban public transport policies. A thorough knowledge of daily travel practices is one requirement for this and accurate collection of individual income data is another which is just as essential.

\section{REFERENCES}

Abdullah, H. J., 2000. Gender and Adjustment in Nigeria's Manufacturing Sector. In: Tsikata, D., Kerr, J. (Eds.), Demanding Dignity: Women Confronting Economic Reforms in Africa. The North-South Institute and Third World Network-Africa, pp. 123-143.

Alderman, H., Chiappori, P.-A., Haddad, L., Hoddinott, J., Kanbur, R., 1995. Unitary versus collective models of the household: is it time to shift the burden of proof? The World Bank Research Observer, 10 (1), 1-19.

Behrens, R., Diaz Olvera, L., Plat, D., Pochet, P., 2006. Collection of passenger travel data in Sub-Saharan African cities: Towards improving survey instruments and procedures. Transport Policy 13 (1), 85-96.

Bocquier, P., Nordman, C. J., Vescovo, A., 2010. Employment vulnerability and earnings in urban West Africa. World Development 38, 1297-1314.

Bryceson, D. F., Mbara, T. C., Maunder, D., 2003. Livelihoods, daily mobility and poverty in Sub-Saharan Africa. Transport Reviews 23, 177-196.

Davern, M., Rodin, H., Beebe, T. J., Call, K. T., 2005. The effect of income question design in health surveys on family income, poverty and eligibility estimates. Health Services Research 40, 1534-1552.

Deaton, A., 1997. The analysis of household surveys: A microeconometric approach to development policy. World Bank Publications, Washington, D. C.

<http://documents.worldbank.org/curated/en/1997/07/694690/analysis-household-surveys-microeconometricapproach-development-policy> (23.08.2014).

Deaton, A., Grosh, M. E., 2000. Consumption. In: Grosh, M. E. and Glewwe, P. W. (Eds.), Designing Household Survey Questionnaires for Developing Countries: Lessons from Ten Years of LSMS Experience. Oxford University Press, Oxford, pp. 91-133.

Deaton, A., Zaidi, S., 2002. Guidelines for Constructing Consumption Aggregates for Welfare Analysis. LSMS Working paper $\mathrm{n}^{\circ} 135$, World Bank Publications, Washington, DC., <http://econ.worldbank.org/external/default/main?pagePK=64165259\&theSitePK=469382\&piPK=64165421 \&menuPK=64166093\&entityID=000094946 02071304010552> (23.08.2014).

De Vreyer, Ph., Roubaud, F. (Eds.), 2013. Urban Labor Markets in Sub-Saharan Africa. AFD-World Bank, Washington, D. C., Africa Development Forum series. DOI: 10.1596/978-0-8213-9781-7.

Diaz Olvera, L., Plat, D., Pochet, P. 2007. Mobilité quotidienne en temps de crise. Belgeo 2, 173-187. <http://belgeo.revues.org/11255> (23.09.2014).

Diaz Olvera, L., Plat, D., Pochet, P. 2008. Household transport expenditure in Sub-Saharan African cities: Measurement and analysis. Journal of Transport Geography 16 (1), 1-13. 
Diaz Olvera, L., Plat, D., Pochet, P., 2013. The puzzle of mobility and access to the city in Sub-Saharan Africa. Journal of Transport Geography 32, 56-64.

Ersado, L., 2006. Income diversification in Zimbabwe: Welfare Implications from Urban and Rural Areas. Policy Research Working Paper n³964, World Bank Publications, Washington, DC. <http://documents.worldbank.org/curated/en/2006/07/6913992/income-diversification-zimbabwe-welfareimplications-urban-rural-areas $>(23.09 .2014)$.

Glick, P., Sahn, D. E., 2000. Schooling of girls and boys in a West African country: the effects of parental education, income, and household structure. Economics of Education Review 19 (1), 63-87.

Fisher, M., Reimer, J. J., Carr, E. A., 2010. Who should be interviewed in surveys of household income? World Development 38 (7), 966-973.

Hansen, K., Kneale, D., 2013. Does how you measure income make a difference to measuring poverty? Evidence from the UK. Social Indicators Research 110, 1119-1140.

Hoddinott, J., Haddad, L., 1995. Does female income share influence household expenditures? Evidence from Côte d'Ivoire. Oxford Bulletin of Economics and Statistics 57 (1), 77-96.

INS - Institut National de la Statistique, 2003. Enquête sur le Cadre de Vie des Populations de Yaoundé et de Douala en 2002, Vol. I. Méthodologie de l'enquête et synthèse des résultats de l'ECAM II sur l'activité et la consommation des ménages, République du Cameroun, Yaoundé.

Iyenda, G., 2005. Street enterprises, urban livelihoods and poverty in Kinshasa. Environment and Urbanization $17,55-67$.

Lechêne, V., 1993. Une revue de la littérature sur les échelles d'équivalence. Economie et Prévision 110-111, 169-182.

Leimdorfer, F., Marie, A. (Eds.), 2003. L’Afrique des citadins. Sociétés civiles en chantier (Abidjan, Dakar). L'Harmattan, Paris.

Lourenço-Lindell, I. 2002. Walking the Tight Rope: Informal Livelihoods and Social Networks in a West African City, Stockholm University, Department of Human Geography. <http://www.divaportal.org/smash/get/diva2:189997/FULLTEXT01.pdfGostaria> (23.08.2014)

Lucas, K., 2011. Making the connections between transport disadvantage and the social exclusion of low income populations in the Tshwane Region of South Africa. Journal of Transport Geography 19, 1320-1334.

Micklewright, J., Schnepf, S.V., 2010. How reliable are income data collected with a single question? Journal of the Royal Statistical Society: Series A (Statistics in Society) 173, 409-429.

Mitlin, D., Satterthwaite, D., Stephens, C., 1996. City inequality. Environment and Urbanization 8, 3-9.

Moore, J. C., Stinson, L. L., Welniak, E. J., 2000. Income measurement error in surveys: A review. Journal of Official Statistics 16 (4), 331-362.

Myers, G. A. (2005). Disposable Cities: Garbage, Governance and Sustainable Development in Urban Africa. Ashgate, Aldershot.

O’Donnell, O., van Doorslaer, E., Wagstaff, A., Lindelow, M., 2008. Analyzing Health Equity Using Household Survey Data: A Guide to Techniques and their Implementation. The World Bank, Washington, DC. <http://siteresources.worldbank.org/INTPAH/Resources/Publications/459843-

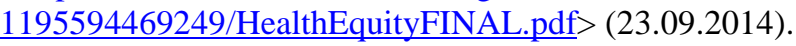

Pettersen, H., 2005. Survey design and sample design in household budget surveys (Chapter XXV). In: United Nations Department of Economic and Social Affairs, Household Sample Surveys in Developing and Transition Countries. United Nations Statistics Division, Studies in Methods, Series F n 96 , pp. 557-570. http://unstats.un.org/unsd/hhsurveys/pdf/Household_surveys.pdf $>$ (04.08.2014).

Posel, D. R., 2001. Intra-family transfers and income-pooling. South African Journal of Economics 69 (3), $501-$ 528.

Rakodi, C., 2005. The urban challenge in Africa. In: Keiner, M., Koll-Schretzenmayr, M., Schmid, W.A. (Eds.), Managing Urban Futures, Sustainability and Urban Growth in Developing Countries. Ashgate, Farnham, pp. 47-70. 
Salon, D., Gulyani, S., 2010. Mobility, poverty, and gender: Travel "choices" of slum residents in Nairobi, Kenya. Transport Reviews 30, 641-657.

Scott, K., 2003. Generating relevant household level data: Multi-topic household surveys. In: Bourguignon, F. and Pereira da Silva, L. (Eds.), The Impact of Economic Policies on Poverty and Income Distribution. Evaluation Techniques and Tools, World Bank-Oxford University Press, Washington, DC., New York.

Séraphin, G., 2000. Vivre à Douala : L'imaginaire et l'action dans une ville africaine en crise. L'Harmattan, Paris.

Sietchiping, R., Permezel, M. J., Ngomsi, C., 2012. Transport and mobility in sub-Saharan African cities: An overview of practices, lessons and options for improvements. Cities 29 (3), 183-189.

Sitrass, 2004. Poverty and Urban Mobility in Douala. SSATP Report No 09/04/Dla, World Bank, 143 p. 〈http://www4.worldbank.org/afr/ssatp/Resources/PapersNotes/Douala_en.pdf> (04.08.2010).

Stopher, P., 2012. Collecting, Managing, and Assessing Data Using Sample Surveys. Cambridge University Press, Cambridge.

Teunissen, T., Sarmiento, O., Zuidgeest, M., Brussel, M., 2015. Mapping Equality in Access: The Case of Bogotá's Sustainable Transportation Initiatives. International Journal of Sustainable Transportation 9 (7), 457467.

Vasconcellos, E. A., 2001. Urban Transport, Environment and Equity. The case for developing countries. Earthscan, London.

Venter, C., Vokolkova, V., Michalek, J., 2007. Gender, residential location, and household travel: Empirical findings from low-income urban settlements in Durban, South Africa. Transport Reviews 27 (6), 653-677.

Yapi-Diahou, A. 2000. Baraques et pouvoirs dans l'agglomération abidjanaise. L'Harmattan, Paris. 